\title{
Para-halogenated benzaldehyde molecules included in cyclodextrins: a combined spectroscopic and thermal analysis
}

\author{
Paulo J. A. Ribeiro-Claro, ${ }^{1 *}$ António M. Amorim da Costa, ${ }^{2}$ Manuel L. Vueba, ${ }^{3}$ \\ M. Eugénia Pina ${ }^{3}$ and Ana M. Amado ${ }^{2}$ \\ ${ }^{1}$ CICECO, Departamento de Química, Universidade de Aveiro, P-3810-193 Aveiro, Portugal \\ 2 Química-Física Molecular, Departamento de Química, Universidade de Coimbra, P-3004-535 Coimbra, Portugal \\ ${ }^{3}$ Laboratório de Galénica e Tecnologia Farmacêutica, Faculdade de Farmácia, Universidade de Coimbra, P-3000-295 Coimbra, Portugal
}

Received 20 May 2005; Accepted 06 August 2005

\begin{abstract}
The inclusion complexes of 4 -X-benzaldehyde guests $(X=F, \mathrm{Cl}, \mathrm{Br})$ in $\alpha-, \beta$-and $\gamma$-cyclodextrins $(\alpha \mathrm{CD}$, $\beta C D$ and $\gamma C D)$ were prepared and characterized by means of thermogravimetry, differential scanning calorimetry (DSC) and vibrational spectroscopy. The stoichiometry of the inclusion complexes ranges from $2: 1$ to $1: 2$, depending on the cavity size of the host. Sensitive vibrational modes such as $\mathrm{C}=\mathrm{O}$ and ring $\mathrm{CH}$ stretching modes were used to monitor the effects of the inclusion process and to assess the preferred inclusion geometry for each host-guest pair. On the whole, the spectral observations suggest that the small $\alpha \mathrm{CD}$ cavity imposes important structural restrictions on the guest molecule, while the larger $\gamma$ CD cavity allows 'liquid-type' intermolecular contacts. Copyright $(2005$ John Wiley \& Sons, Ltd.
\end{abstract}

KEYWORDS: cyclodextrins; benzaldehyde derivatives; hydrogen bonding; thermal analysis

\section{INTRODUCTION}

Cyclodextrins (CDs) are known to form inclusion complexes with a wide variety of molecules, ${ }^{1,2}$ the only requirement being that at least part of the guest can penetrate into the cavity. This ability gives them relevant practical benefits in several areas, namely, in the pharmaceutical, food, cosmetic and agricultural industries. ${ }^{3-14}$ Many active ingredients, such as flavours and drugs, are protected from degradation and/or evaporation upon encapsulation in the CD cavity. Moreover, CDs can greatly increase the solubility of waterinsoluble substances, as well as control the release of encapsulated ingredients, flavours or drugs.

Different analytical techniques have been used to determine whether the product obtained is a true inclusion complex, as well as to analyse the molecular structure and interactions established in the host-guest complex. ${ }^{4,5,15-26}$ Raman spectroscopy and differential scanning calorimetry (DSC) are among the most accessible experimental techniques for the study of inclusion complexes in the solid state. ${ }^{4-6,18-29}$

*Correspondence to: Paulo J. A. Ribeiro-Claro, CICECO, Departamento de Química, Universidade de Aveiro, P-3810-193 Aveiro, Portugal. E-mail: pclaro@dq.ua.pt

Contract/grant sponsor: Portugese Foundation for Science and Technology; Contract/grant number: POCTI/QUI/35 408/99.
The aim of the present work is to pursue the study and the characterization of the interactions occurring in the $\alpha-, \beta$ - and $\gamma \mathrm{CD}$ inclusion complexes with aromatic guests. ${ }^{18-20}$ The following benzaldehyde derivatives are considered as guest molecules: 4-fluorobenzaldehyde (4FB), 4-chlorobenzaldehyde $(4 \mathrm{ClB})$ and 4-bromobenzaldehyde (4BrB). The guest : host : $\mathrm{H}_{2} \mathrm{O}$ stoichiometries of the inclusion complexes are inferred from DSC and thermogravimetric (TG) data. Raman spectroscopy is used to characterize the complexes and rationalize the preferences of guest inclusion orientation as well as to establish the host-guest intermolecular interactions. As done previously, ${ }^{18-20}$ Fourier transform infrared (FTIR) spectroscopy has not been used, as most of the guest bands are either too weak or strongly overlapped by $\mathrm{CD}$ bands (even the strong $\nu C=O$ mode is masked by the H-O-H deformation modes of the structural water molecules).

\section{EXPERIMENTAL}

Materials and preparation of inclusion complexes Cyclodextrins $(\alpha-, \beta$ - and $\gamma \mathrm{CD})$ were kindly offered by Wacker Chemie GmbH, Germany. The benzaldehyde derivatives $(4 \mathrm{FB}, 4 \mathrm{ClB}$ and $4 \mathrm{BrB})$ were obtained commercially (Aldrich) and were used without further purification. 
The inclusion complexes of the liquid $4 \mathrm{FB}$ guest were prepared by mixing the benzaldehyde derivative with an aqueous solution of $\mathrm{CD}$ (dropwise addition with strong agitation) at room temperature. In the case of the solid benzaldehyde derivatives $(4 \mathrm{ClB}$ and $4 \mathrm{BrB})$, because of their low solubility in water, the $C D$ solution was kept under strong agitation in a bath at $50{ }^{\circ} \mathrm{C}$ during the guest addition.

In both cases, the process led to the rapid formation of white precipitates, which were filtered and allowed to dry for a few days, at room temperature and ambient relative humidity conditions. After this, the precipitates were ground to a fine powder. The complexes were found to be stable for several months.

\section{Differential scanning calorimetry (DSC) and thermogravimetric (TG) analysis}

The DSC measurements were carried out using a Shimadzu DSC-50 differential scanning calorimeter with a thermal analyser, Shimadzu TA-50. Samples were heated in sealed aluminium pans under a nitrogen flow of $20 \mathrm{ml} / \mathrm{min}$, using a sealed empty pan as reference, and at a heating rate of $10^{\circ} \mathrm{C} / \mathrm{min}$, over the temperature range from 25 to $400^{\circ} \mathrm{C}$.

The thermogravimetric analysis (TGA) measurements were performed on a TGA-50 Shimadzu apparatus. The accurately weighed samples were placed in aluminium pans and sealed. All samples were kept for $5 \mathrm{~min}$ at $20^{\circ} \mathrm{C}$, before heating up to $400{ }^{\circ} \mathrm{C}$, at a scanning rate of $2^{\circ} \mathrm{C} / \mathrm{min}$.

\section{FT-Raman spectroscopic experiments}

The room temperature FT-Raman spectra were recorded on a RFS-100 Bruker FT spectrometer using a Nd:YAG laser with the excitation wavelength of $1064 \mathrm{~nm}$. Each spectrum is the average of two repeated measurements of 150 scans each and $2 \mathrm{~cm}^{-1}$ resolution. Samples were sealed in Kimax glass tubes of $0.8-\mathrm{mm}$ inner diameter. Higher-temperature spectra were recorded on a Jobin-Yvon T64000 triple monochromater system (focal length $0.640 \mathrm{~m}$, aperture $\mathrm{f} / 7.5$ ) with a nonintensified charge-coupled device (CCD) detector and an $\mathrm{Ar}^{+}$laser as the excitation source, using a home-made Harney-Miller assembly. ${ }^{30}$ An integration time of $5 \mathrm{~s}$ and two scans were used.

\section{Theoretical calculations}

Theoretical calculations were carried out using the Gaussian $98 \mathrm{~W}$ program package. ${ }^{31}$ Full geometry optimizations and vibrational wavenumber calculations of the guest molecules were performed at the standard B3LYP /6-31G* theory level. The effect of the polarity of the environment on the vibrational wavenumbers of the guest molecules was evaluated using the self-consistent reaction field approach, with the Self-Consistent Isodensity Polarized Continuum Model (SCIPCM). ${ }^{32}$ This approach (SCI-PCM at the B3LYP/6-31G* level) was found to be appropriate to predict the wavenumber dependence on the dielectric media ${ }^{33}$ and allowed the comparison with previous studies. ${ }^{20}$

\section{RESULTS AND DISCUSSION \\ Differential scanning calorimetry (DSC) and thermogravimetric (TG) analysis}

When guest molecules are embedded in CD cavities or in the crystal lattice, their melting, boiling or sublimation points generally shifts to a different temperature. Moreover, as inclusion compounds of CDs are generally prepared in aqueous media, they must be considered as ternary water/CD/guest systems. DSC combined with TGA represents an analytical tool of first choice for an accurate assessment of the inclusion-compound stoichiometry.

The DSC traces of the pure solid guests $4 \mathrm{ClB}$ and $4 \mathrm{BrB}$ (the DSC curve of pure 4FB was not obtained because of its liquid state) exhibit a sharp endothermic peak centred at 48 and $58^{\circ} \mathrm{C}$, respectively, corresponding to the melting points of those benzaldehyde derivatives (Sigma-Aldrich tabulated values are $47-50$ and $55-58{ }^{\circ} \mathrm{C}$, respectively). In each case, two additional broad endothermic peaks are also observed. In the case of $4 \mathrm{ClB}$, the first one is centred at $114^{\circ} \mathrm{C}$, and can be associated with thermal flashing of the sample (Sigma-Aldrich tabulated value is $87^{\circ} \mathrm{C}$ ), while the second one is centred at $160^{\circ} \mathrm{C}$, and probably indicates thermal degradation of the sample. For $4 \mathrm{BrB}$, these two effects yield the broad peaks centred at $124^{\circ} \mathrm{C}$ (SigmaAldrich tabulated flashing point value is $108^{\circ} \mathrm{C}$ ) and $172^{\circ} \mathrm{C}$, respectively. On the other hand, the DSC and TGA traces of $\alpha-, \beta$ - and $\gamma \mathrm{CD}$ are in agreement with those reported in the literature. $^{21}$

Figure 1 shows the DSC and TGA traces of $\alpha \mathrm{CD} \bullet 4 \mathrm{BrB}$ inclusion complex. The DSC curves of pure $4 \mathrm{BrB}$ and $\alpha \mathrm{CD}$ are included for comparison. The thermal curves (DSC and TG) of the remaining CD inclusion complexes are not shown, since they present the same general profile and main features exhibited by the $\alpha \mathrm{CD} \bullet 4 \mathrm{BrB}$ complex.

The DSC trace of $\alpha \mathrm{CD} \bullet 4 \mathrm{BrB}$ complex displays two endothermic peaks between 20 and $104^{\circ} \mathrm{C}$ due to the dehydration of the complex. The occurrence of these two bands indicates the existence of distinctly bound water molecules in the inclusion complex. This stepwise dehydration is evident in the TGA curve and resembles the effect observed for $\alpha \mathrm{CD}$ itself. ${ }^{21}$ However, the broadening and shifting of the bands indicate differently linked water structures in the two systems ( $\alpha \mathrm{CD}$ and $\alpha \mathrm{CD} \bullet 4 \mathrm{BrB}$ ). Moreover, the absence of the two guest peaks centred at 124 and $172{ }^{\circ} \mathrm{C}$ confirms the inclusion of the guest (the two peaks are present in the DSC trace of the physical mixture $\alpha \mathrm{CD}+4 \mathrm{BrB}$ ).

The small feature centred at $269^{\circ} \mathrm{C}$ is associated with release of the guest from the complex. The mass loss leads to a baseline decline in the TGA curve in the same temperature range (Fig. 1).

On the basis of the combined DSC/TGA, the stoichiometries of the inclusion complexes were achieved by quantification of the different mass losses identified in the TG curves, upon temperature increase. The results are summarized in 
(a)

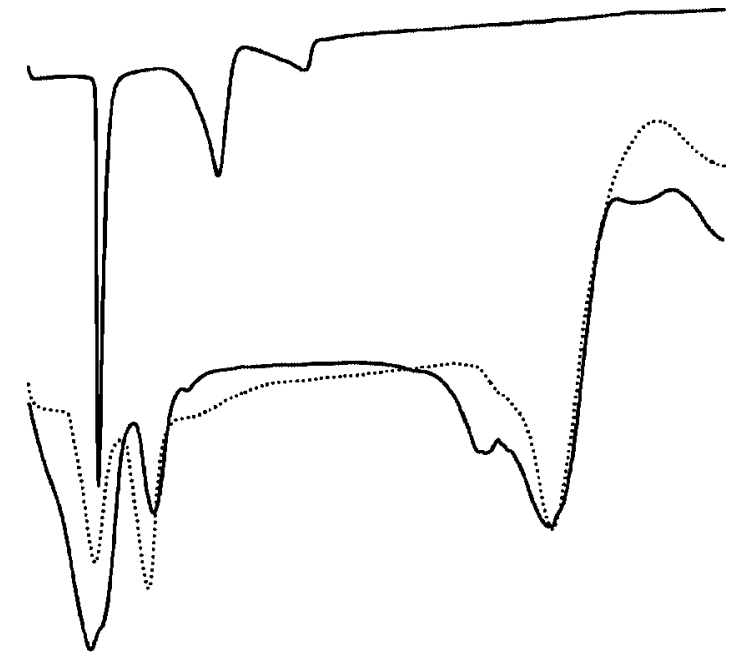

(c)

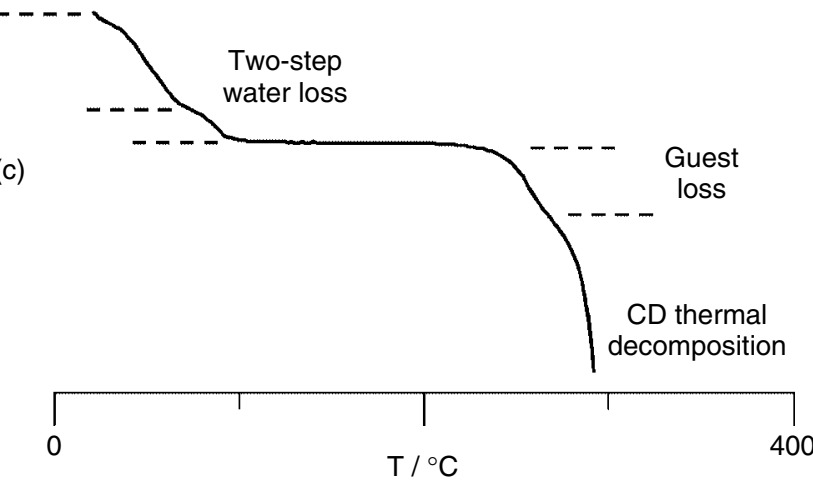

Figure 1. Thermal analysis: (a) DSC curve of pure solid $4 \mathrm{BrB}$, (b) DSC curve of $\alpha \mathrm{CD}$ (dashed line) and $\alpha \mathrm{CD} \cdot 4 \mathrm{BrB}$ complex (filled line) and (c) TG curve of $\alpha \mathrm{CD} \bullet 4 \mathrm{BrB}$ complex.

Table 1. For all guests, the $\alpha \mathrm{CD}$ inclusion complexes present two host molecules per guest molecule $(2: 1)$, while in the case of the $\beta C D$ complexes the stoichiometry becomes $1: 1$. Finally, the wider $\gamma \mathrm{CD}$ cavity is able to accommodate two guest benzaldehyde molecules, and presents a clear 1:2 stoichiometry.
Concerning the water content of the samples, the $\alpha \mathrm{CD}$ inclusion complexes present the lowest number of water molecules per CD (5 to 7). For $\beta C D$ and $\gamma \mathrm{CD}$ inclusion complexes, the number of water molecules ranges from 9 to 13 (Table 1). These values are in agreement with the reported values for similar inclusion complexes. The $\mathrm{X}$-ray structure of the $\alpha \mathrm{CD} \cdot$ benzaldehyde complex shows the presence of six interstitial water molecules. ${ }^{34}$ Thermogravimetric analyses of $\alpha \mathrm{CD} \cdot 4-\mathrm{F}$-phenol, ${ }^{35} \beta \mathrm{CD} \cdot$ benzaldehyde ${ }^{36}$ and $\beta C D \bullet$ anisaldehyde ${ }^{37}$ yield nine water molecules per CD. Although there is no information concerning the number of intra-cavity and extra-cavity (interstitial) water molecules, the TG curves clearly show the presence of differently bound water molecules in all systems. For instance, in the TG curve of the $\alpha \mathrm{CD} \bullet 4 \mathrm{BrB}$ complex (Fig. 1), there are two well-defined steps in the water-loss region, corresponding to the mass of two water molecules $\left(3.31 \%\right.$ at $\left.c a 50{ }^{\circ} \mathrm{C}\right)$ and three water molecules $\left(4.94 \%\right.$ at $\left.c a 75^{\circ} \mathrm{C}\right)$.

\section{Vibrational spectra}

As in the previous report, ${ }^{20}$ emphasis will be given to the $\mathrm{C}=\mathrm{O}$ stretching mode $(\nu \mathrm{C}=\mathrm{O})$, as it is relatively free from interfering bands of the $\mathrm{CD}$ host and is particularly sensitive to the environment around this molecular fragment. Thus, the analysis of this spectral region can yield valuable information concerning the involvement of the $\mathrm{C}=\mathrm{O}$ groups in intermolecular host-guest and/or guest-guest interactions. The effects of $C D$ inclusion on other spectral regions, namely, those assigned to the ring $\mathrm{CC}$ and $\mathrm{CH}$ stretching modes $(\nu \mathrm{CC}$ and $\nu \mathrm{CH})$ and to the $\mathrm{CX}$ stretching mode $(\nu \mathrm{CX})$, are also analysed.

The $\nu C=O$ region

Figure 2 presents the $1650-1750 \mathrm{~cm}^{-1}$ Raman spectral region of pure $4 \mathrm{XB}$ derivatives $(\mathrm{X}=\mathrm{F}, \mathrm{Cl}$ and $\mathrm{Br})$ and their inclusion complexes with $\alpha-, \beta$ - and $\gamma \mathrm{CD}$. Since $4 \mathrm{ClB}$ and $4 \mathrm{BrB}$ are solids at room temperature, the spectra of pure guests reported herein are from melted samples, for easier

Table 1. Calculated stoichiometry of the inclusion complexes based on DSC and TGA

\begin{tabular}{lcccc}
\hline System & $\%($ Guest $)$ & $\%\left(\mathrm{H}_{2} \mathrm{O}\right)$ & $\begin{array}{c}\text { Complex } \\
\text { stoichiometry }\end{array}$ & $\begin{array}{c}\text { Water molecules } \\
\text { per CD }\end{array}$ \\
\hline$\alpha \mathrm{CD} \bullet 4 \mathrm{FB}$ & 6.79 & 10.78 & $(\alpha \mathrm{CD})_{2} \bullet 4 \mathrm{FB}$ & $7 \mathrm{H}_{2} \mathrm{O}$ \\
$\alpha \mathrm{CD} \bullet \mathrm{ClB}$ & 5.37 & 9.73 & $(\alpha \mathrm{CD})_{2} \bullet 4 \mathrm{ClB}$ & $6 \mathrm{H}_{2} \mathrm{O}$ \\
$\alpha \mathrm{CD} \bullet \mathrm{BrB}$ & 4.51 & 8.25 & $(\alpha \mathrm{CD})_{2} \bullet 4 \mathrm{BrB}$ & $5 \mathrm{H}_{2} \mathrm{O}$ \\
$\beta \mathrm{CD} \bullet 4 \mathrm{FB}$ & 8.93 & 11.55 & $\beta \mathrm{CD} \bullet 4 \mathrm{FB}$ & $9 \mathrm{H}_{2} \mathrm{O}$ \\
$\beta \mathrm{CD} \bullet 4 \mathrm{ClB}$ & 8.77 & 15.25 & $\beta \mathrm{CD} \bullet 4 \mathrm{ClB}$ & $13 \mathrm{H}_{2} \mathrm{O}$ \\
$\beta \mathrm{CD} \bullet 4 \mathrm{BrB}$ & 6.44 & 15.00 & $\beta \mathrm{CD} \bullet 4 \mathrm{BrB}$ & $12 \mathrm{H}_{2} \mathrm{O}$ \\
$\gamma \mathrm{CD} \bullet 4 \mathrm{FB}$ & 14.25 & 10.25 & $\gamma \mathrm{CD} \bullet 4 \mathrm{FB})_{2}$ & $10 \mathrm{H}_{2} \mathrm{O}$ \\
$\gamma \mathrm{CD} \bullet 4 \mathrm{ClB}$ & 14.60 & 9.69 & $\gamma \mathrm{CD} \bullet(4 \mathrm{ClB})_{2}$ & $9 \mathrm{H}_{2} \mathrm{O}$ \\
$\gamma \mathrm{CD} \bullet \mathrm{BrB}$ & 12.58 & 13.31 & $\gamma \mathrm{CD} \bullet(4 \mathrm{BrB})_{2}$ & $13 \mathrm{H}_{2} \mathrm{O}$ \\
\hline
\end{tabular}



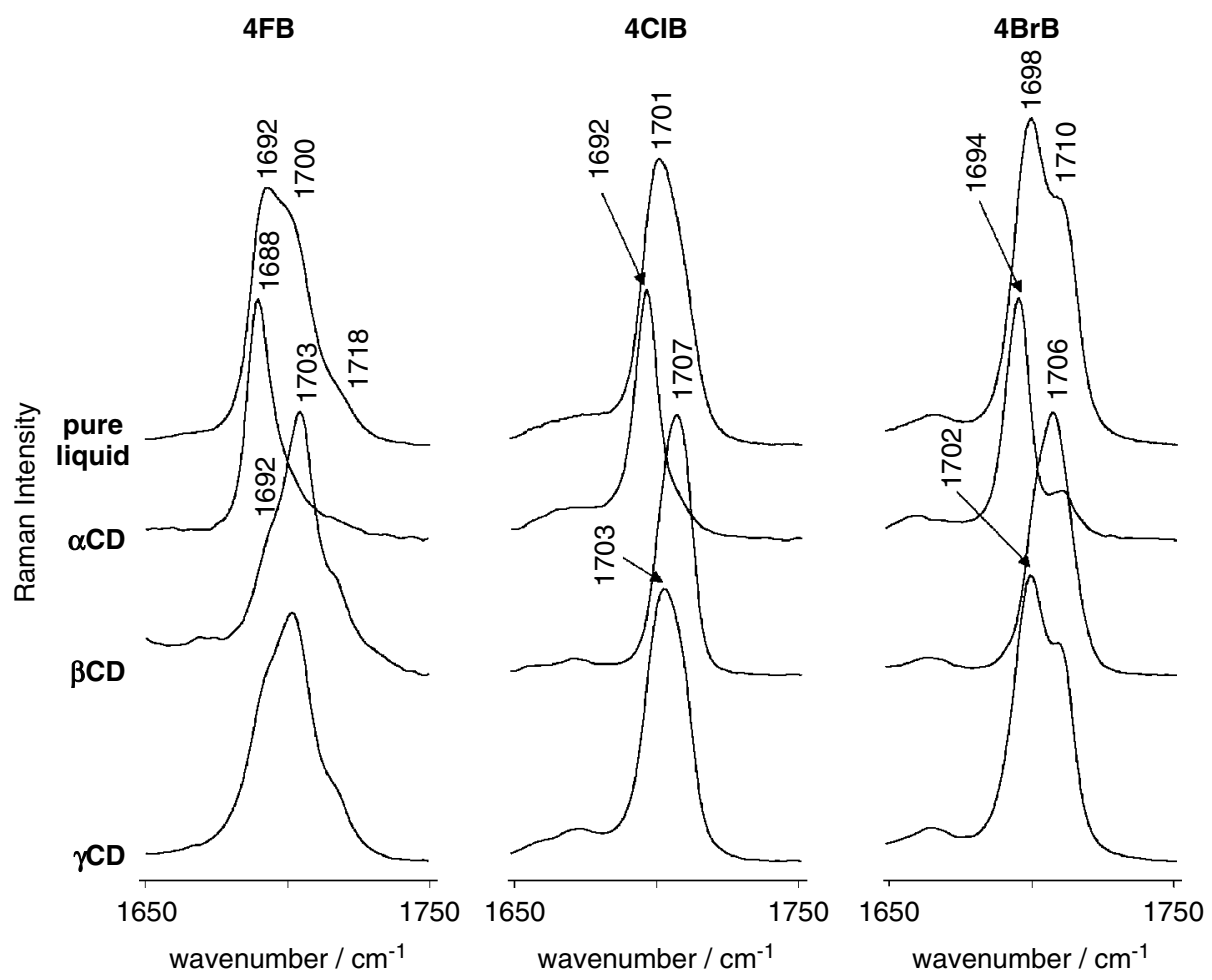

Figure 2. Raman spectra in the $1650-1750 \mathrm{~cm}^{-1}$ region of the pure $4 \mathrm{XB}$ derivatives $(\mathrm{X}=\mathrm{F}, \mathrm{Cl}, \mathrm{Br})$ and of their $\alpha$-, $\beta$ - and $\gamma \mathrm{CD}$ inclusion complexes.

comparison with $4 \mathrm{FB}$ (melting points are $313 \mathrm{~K}$ for $4 \mathrm{ClB}$ and $328 \mathrm{~K}$ for $4 \mathrm{BrB})$.

The observation of this spectral region clearly shows a splitting of the $v \mathrm{C}=\mathrm{O}$ band envelope in the three pureliquid guests. The splitting of the carbonyl band has been assigned to Fermi resonance ${ }^{38}$ or, as reported more recently, to dimerization equilibrium through $\mathrm{CH} \cdots \mathrm{O}=\mathrm{C} .{ }^{39-43}$ In the case of $4 \mathrm{FB}$, there is strong experimental evidence supporting the latter assignment. ${ }^{43}$ For $4 \mathrm{ClB}$ and $4 \mathrm{BrB}$, the $\mathrm{CH} \cdots \mathrm{O}=\mathrm{C}$ contacts are present in the crystal structure, ${ }^{44}$ and the preliminary vibrational data available for the liquid - e.g. temperature and solvent effects (results not shown) - suggest the same assignment.

The encapsulation process of the three benzaldehyde derivatives leads to significant changes in the $\nu \mathrm{C}=\mathrm{O}$ band envelope, depending on the CD cavity dimensions. Inclusion of the three guests in the $\alpha \mathrm{CD}$ cavity results in a significant narrowing of the $\nu \mathrm{C}=\mathrm{O}$ band envelope. In addition, the $\nu \mathrm{C}=\mathrm{O}$ envelope maximum shifts downwards by $\mathrm{ca} 4-5 \mathrm{~cm}^{-1}$ in relation to its original position in the free guest spectra. In contrast, the inclusion of the three guests in $\gamma \mathrm{CD}$ leaves the $\nu \mathrm{C}=\mathrm{O}$ band profile with the same general pattern as that of the pure liquid spectra. The similarity of the $\nu \mathrm{C}=\mathrm{O}$ band profiles of the $\gamma \mathrm{CD}$ complexes with that of the corresponding pure-liquid guest increases from $4 \mathrm{FB}$ to $4 \mathrm{BrB}$. The effects of $\beta C D$ inclusion on the $\nu \mathrm{C}=\mathrm{O}$ band profile are somewhere in between the above-described ones. The presence of more than one band is evident, but their intensity ratios are clearly different from those observed for the pure-liquid guests, since the inclusion leads to an intensity transfer to the higher-wavenumber side of the $\nu \mathrm{C}=\mathrm{O}$ band envelope.

In a previous report on benzaldehyde inclusion complexes, ${ }^{20}$ similar spectral changes upon inclusion have been interpreted in terms of a balance between 'free' and 'hydrogen-bonded' $\mathrm{C}=\mathrm{O}$ groups. The same interpretation can be used in the present case. Both X-ray data and spectroscopic studies of the pure guests ${ }^{43,44}$ support the assignment of the two bands observed in the $\nu \mathrm{C}=\mathrm{O}$ region to hydrogen-bonded $\mathrm{C}=\mathrm{O}$ groups (lower wavenumber) and free $\mathrm{C}=\mathrm{O}$ groups (higher wavenumber).

Since both bands are present in the vibrational spectra of the $\gamma \mathrm{CD}$ complexes, it is assumed that the $\gamma \mathrm{CD}$ cavity allows a 'liquidlike' distribution of the guest molecules, with several inclusion geometries and hydrogen-bond contacts. In the case of the $\beta C D$ complexes, the results are consistent with a decrease of the guest disorder, probably due to the smaller cavity size of $\beta C D$ (relative to $\gamma \mathrm{CD}$ ). The strong $\nu \mathrm{C}=\mathrm{O}$ band is assigned to isolated $\mathrm{C}=\mathrm{O}$ groups, although the presence of a second band in the lower wavenumber region indicates a second inclusion geometry, with a different $\mathrm{C}=\mathrm{O}$ environment. Concerning the $\alpha \mathrm{CD}$ complexes, the sharper $\nu \mathrm{C}=\mathrm{O}$ bands suggest a severely rigid inclusion geometry, which can be explained from the steric constraints imposed by the small cavity size. The tail to the higher wavenumbers 

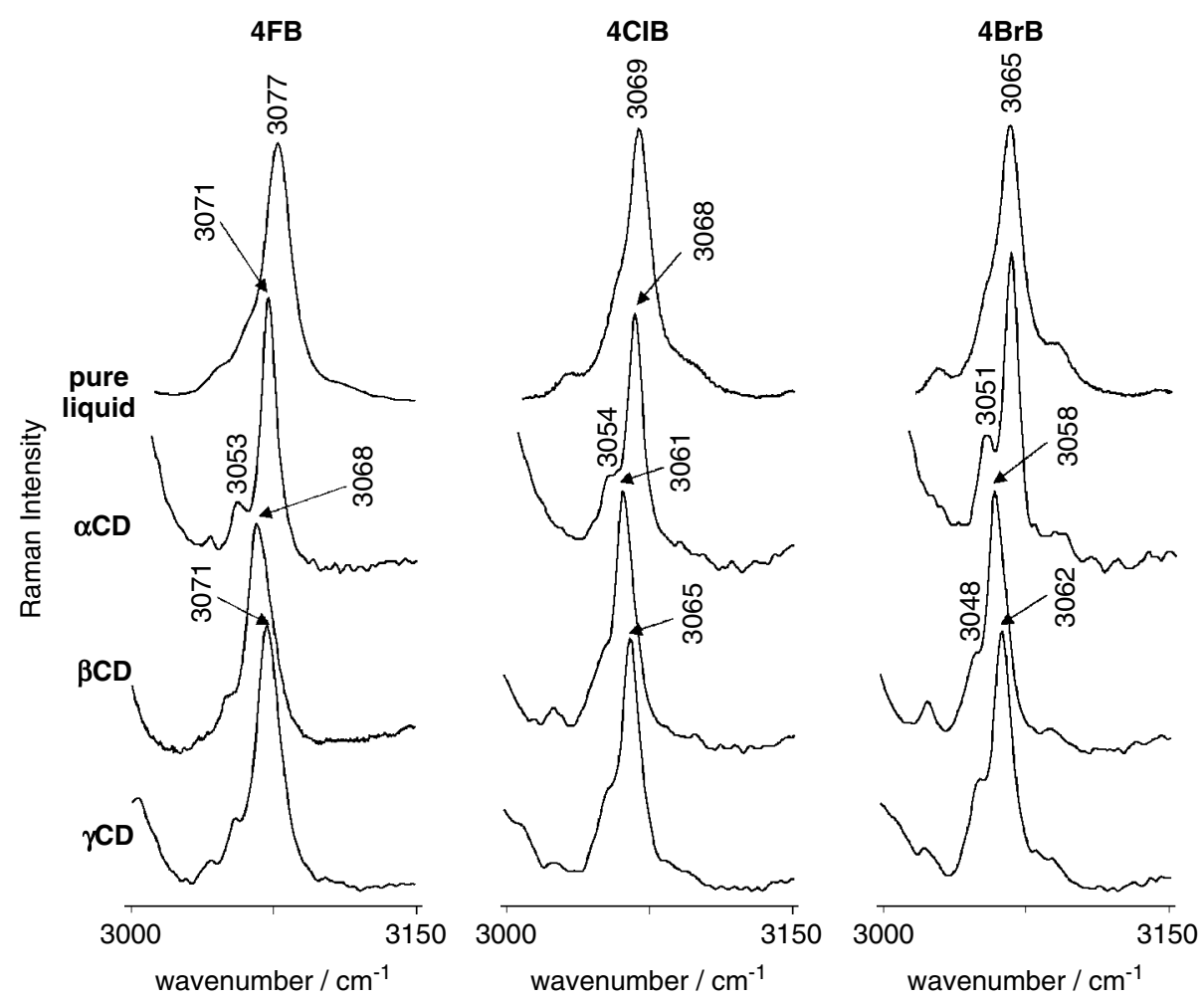

Figure 3. Raman spectra in the $3000-3150 \mathrm{~cm}^{-1}$ region of the pure $4 \mathrm{XB}$ derivatives $(\mathrm{X}=\mathrm{F}, \mathrm{Cl}, \mathrm{Br})$ and of their $\alpha-, \beta$ - and $\gamma \mathrm{CD}$ inclusion complexes.

observed for $4 \mathrm{FB}$ and $4 \mathrm{ClB}$ complexes, as well as the band at $1706 \mathrm{~cm}^{-1}$ in the $4 \mathrm{BrB}$ complex, may be ascribed to the presence of extra-cavity guest molecules.

\section{The $\nu \mathrm{CH}$ region}

Figure 3 presents the Raman spectra of the pure $4 \mathrm{XB}$ derivatives (liquid) and their $\alpha-, \beta$ - and $\gamma \mathrm{CD}$ inclusion complexes in the $3000-3150 \mathrm{~cm}^{-1}$ spectral region, which has been assigned to the aromatic ring $\nu \mathrm{CH}$ modes. ${ }^{43}$

Previous studies of $\mathrm{CD}$ complexes with aromatic guests show that the ring $\nu \mathrm{CH}$ modes may be sensitive to the inclusion process. ${ }^{18-20}$ For instance, inclusion of benzaldehyde in the $\alpha \mathrm{CD}$ cavity yields a significant upwards shifting (blue-shift) of the $\nu \mathrm{CH}$ band envelope, ${ }^{20}$ which has been correlated with the $\mathrm{CH} \cdots \mathrm{O}=\mathrm{C}$ intermolecular hydrogen bond observed in the X-ray structure of this complex. ${ }^{34}$

As can be seen in Fig. 3, there are two main effects resulting from the inclusion process of the benzaldehyde derivatives reported herein: the narrowing of the band profile (which is particularly evident for the $\alpha \mathrm{CD}$ complexes) and the large downward shifts of the band maxima in the $\beta C D$ complexes. In agreement with the observations on the $v C=O$ region, the smallest differences relative to the pure liquid are observed for the $\gamma \mathrm{CD}$ complexes.

The clear band narrowing observed in the $\alpha \mathrm{CD}$ complexes relative to the pure liquids can be easily related with the structural rigidity imposed by the CD cavity size. Somewhat less straightforward is the interpretation of the $7-10 \mathrm{~cm}^{-1}$ red-shift of the $\nu \mathrm{CH}$ band in the $\beta C D$ complexes. The complexes with $\alpha \mathrm{CD}$ and $\gamma \mathrm{CD}$ present clearly smaller shifts ( ca $0-5 \mathrm{~cm}^{-1}$ ), and this is an evidence of the distinct inclusion geometry in $\beta \mathrm{CD}$ complexes relative to $\alpha \mathrm{CD}$ and $\gamma \mathrm{CD}$.

\section{Other spectral regions}

Apart from the $\nu \mathrm{C}=\mathrm{O}$ and the aromatic $\nu \mathrm{CH}$ modes, which occur in regions free from $\mathrm{CD}$ bands, other guest modes cannot be systematically used to follow the effects of the inclusion process, because of the interference of the host bands. However, in some cases a relevant guest mode can be observed in one of the small windows present in the Raman spectra of $\mathrm{CD}$ hosts.

Figure 4 shows the Raman spectra of the pure $4 \mathrm{FB}$ and its $\mathrm{CD}$ inclusion complexes in the $\nu \mathrm{CF}$ spectral region $\left(1165-1285 \mathrm{~cm}^{-1}\right)$. For pure $4 \mathrm{FB}$, the $\nu \mathrm{CF}$ mode yields a welldefined band at $1227 \mathrm{~cm}^{-1}$, in the vicinity of the $\nu \mathrm{C}-\mathrm{C}(\mathrm{HO})$ band $\left(1203 \mathrm{~cm}^{-1}\right){ }^{43}$ The $\mathrm{CD}$ inclusion of $4 \mathrm{FB}$ leads to an upward shifting of the $\nu C F$ vibrational mode, which is significantly larger upon $\alpha \mathrm{CD}$ inclusion in relation to the one that occurs for the wider CDs $\left(\Delta v=+10 \mathrm{~cm}^{-1} v s\right.$ $\left.\Delta v=+3 \mathrm{~cm}^{-1}\right)$. The significant shift of the $\nu \mathrm{CF}$ mode must be related with the different inclusion environment provided by $\alpha \mathrm{CD}$ relative to $\beta$ and $\gamma \mathrm{CD}$, and further supports the proposal of distinct inclusion geometries for these complexes. 


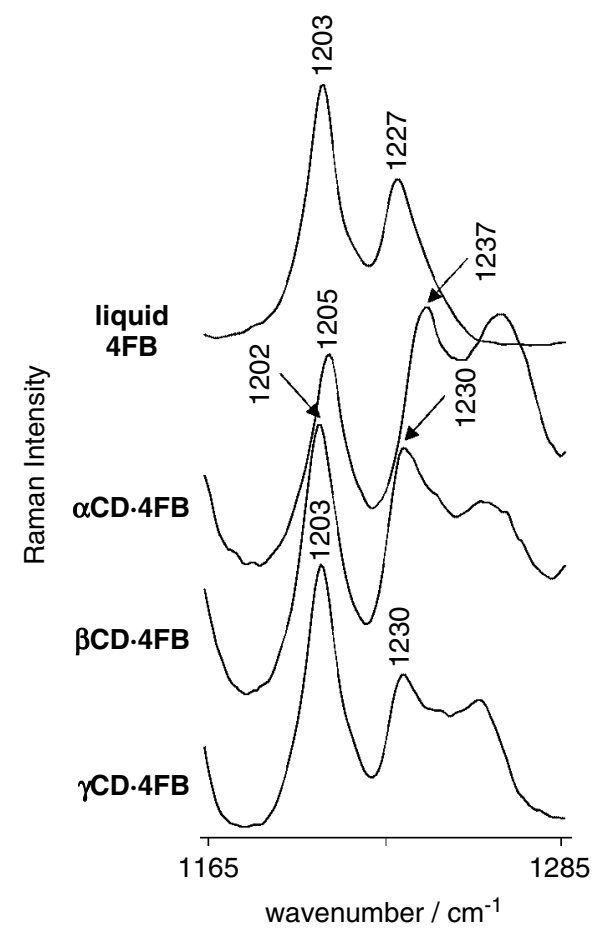

Figure 4. Raman spectra in the $1165-1285 \mathrm{~cm}^{-1}$ region of the pure $4 \mathrm{FB}$ and of its $\alpha-, \beta$ - and $\gamma \mathrm{CD}$ inclusion complexes.

Another interesting case is observed for the $4 \mathrm{ClB}$ systems in the region of the ring $\nu C C$ modes at $c a 1600 \mathrm{~cm}^{-1}$ (8a/8b pair according to Wilson's notation for aromatic molecule ${ }^{45}$ ). In the pure guest, the band intensity ratio of the $1596 / 1588 \mathrm{~cm}^{-1}$ band pair was found to be temperature dependent (results not shown). As shown in Fig. 5, this intensity ratio is also sensitive to the inclusion process. In fact, the inclusion in $\gamma \mathrm{CD}$ mimics the effect of temperature increase, while the inclusion in $\alpha \mathrm{CD}$ acts as in a temperature decrease. Although the temperature dependence of the $1595 / 1588 \mathrm{~cm}^{-1}$ intensity ratio is not yet fully understood, Fig. 5 stresses the conclusions drawn from the previous spectral regions: the $\nu \mathrm{CC}$ band profile in the $\gamma \mathrm{CD}$ complex is nearly identical to the one of the pure guest, while a large change is observed for the $\alpha \mathrm{CD}$ complex. The effect of $\beta C D$ inclusion constitutes an intermediate situation, with the two components of the doublet presenting almost equal Raman intensity.

\section{Theoretical calculations}

Theoretical calculations can be used to assign the vibrational spectra and to predict the wavenumber shifts resulting from both specific and non-specific interactions with the CD cavity (e.g. hydrogen bonding vs changing dielectric environment). Since the CD cavity is known to have lower polarity ${ }^{46}$ than the region of the rims, the inclusion geometry would affect the $\nu \mathrm{C}=\mathrm{O}$ and $\nu \mathrm{CH}$ modes in a predictable way. ${ }^{33}$

Wavenumber calculations for the guest molecules in different dielectric media show that an increase of solvent

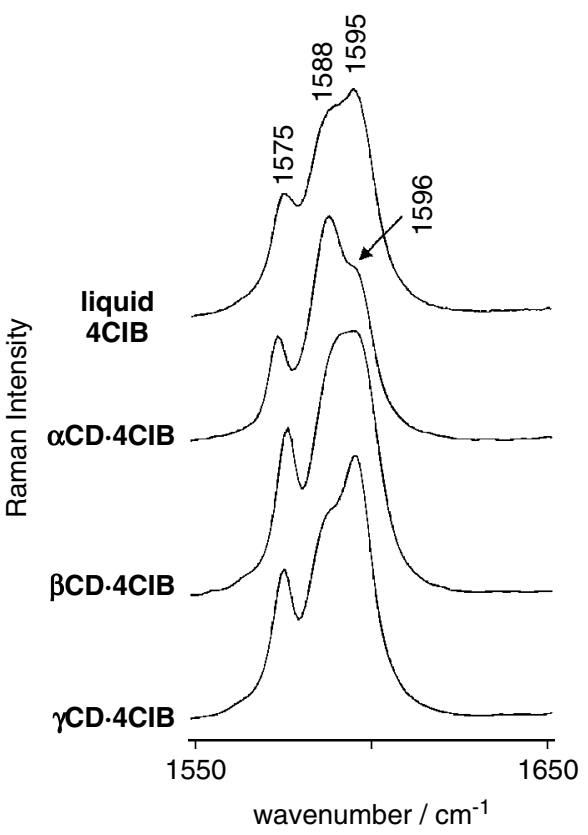

Figure 5. Raman spectra, in the $1550-1650 \mathrm{~cm}^{-1}$ region, of the pure $4 \mathrm{CIB}$ derivatives and of its $\alpha^{-}, \beta$ - and $\gamma \mathrm{CD}$ inclusion complexes.

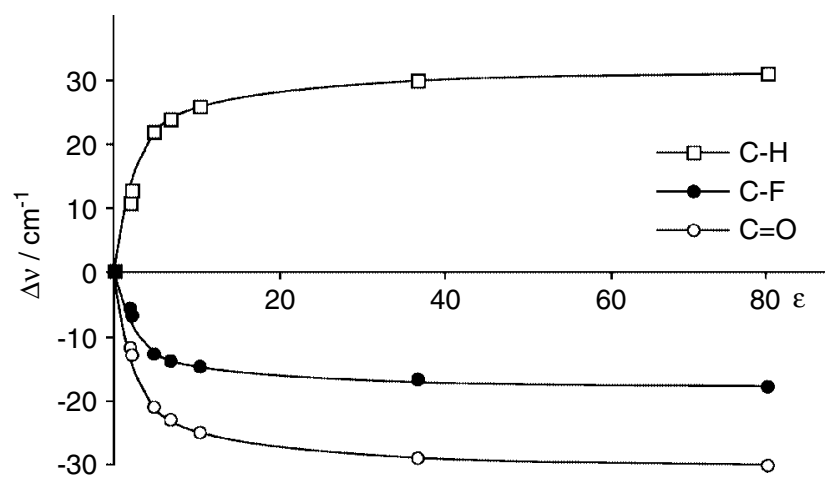

Figure 6. Plot of calculated wavenumber shifts (in $\mathrm{cm}^{-1}$ ) of $\mathrm{CH}, \mathrm{CF}$ and $\mathrm{C}=\mathrm{O}$ stretching modes as a function of the dielectric constant of the medium (SCI-PCM model). The dashed lines are just eye-guides.

(or environment) polarity leads to a wavenumber decrease (red-shift) of both the $\nu \mathrm{C}=\mathrm{O}$ and the $\nu \mathrm{CX}$ modes, while it promotes a blue-shift of the $\nu \mathrm{CH}$ modes (Fig. 6). These results can be used to assist the interpretation of the observed spectral shifts (Figs 2-5).

The results for the $\nu \mathrm{CF}$ mode of $4 \mathrm{FB}$ are somewhat straightforward. The inclusion in the wider $\beta$ - and $\gamma \mathrm{CD}$ yields a much larger upwards shift $\left(+10 \mathrm{~cm}^{-1}\right)$ than the inclusion in $\alpha \mathrm{CD}\left(+3 \mathrm{~cm}^{-1}\right)$. These shifts are in agreement with the proposed stoichiometry determined for the complexes: the $2: 1$ ratio in the $\alpha \mathrm{CD} \bullet 4 \mathrm{FB}$ complex implies that both substituents of the guest are in an intra-cavity environment (low dielectric constant for the $\mathrm{C}-\mathrm{F}$ group), while in the $1: 1$ 
and $1: 2$ ratio of the wider $\beta$ - and $\gamma \mathrm{CD}$ complexes, a deeper inclusion of the guest probably leaves the $\mathrm{C}-\mathrm{F}$ terminal close to one of the $\mathrm{OH}$-rims.

Concerning the $\nu \mathrm{CH}$ modes, the $\mathrm{ca} 7-10 \mathrm{~cm}^{-1}$ downward shift (red-shift) observed for $\beta C D$ is consistent with the change from a high dielectric medium (pure guest) to a low dielectric environment (the $\beta C D$ cavity). This observation suggests deep inclusion geometry of the aromatic ring in the $\beta C D$ cavity. The small shifts observed for both the $\alpha \mathrm{CD}$ and the $\gamma \mathrm{CD}$ complexes cannot be so easily interpreted. However, one can assume two reasonable explanations: (i) $\alpha \mathrm{CD}$ does not allow the full inclusion of the aromatic ring, leaving the $\mathrm{C}-\mathrm{H}$ groups in the inter-rims region between $\mathrm{CDs}$ and (ii) in $\gamma \mathrm{CD}$, the presence of two guests (and even $\mathrm{H}_{2} \mathrm{O}$ molecules) affects significantly the dielectric properties of the host cavity.

The effects of the inclusion process on the $\nu \mathrm{C}=\mathrm{O}$ mode seem to be related with specific interactions and not with the dielectric environment. In fact, the observed shifts are generally opposed to those predicted from Fig. 6. For instance, the 1:2 stoichiometry of the $\alpha \mathrm{CD}$ complexes indicates an intra-cavity position of the $\mathrm{C}=\mathrm{O}$ group. The red-shift observed for this mode is not consistent with a lowpolarity medium and must result from specific interactions, such as hydrogen bonding with intra-cavity water molecules.

\section{CONCLUSIONS}

The combined results from TGA, Raman spectroscopy and $a b$ initio calculations allow a consistent description of the inclusion complexes herein studied. The description is in agreement with previous vibrational spectroscopic studies of CD complexes with aromatic guests, ${ }^{18-20}$ and provides further information on the inclusion process in CD hosts.

In the case of the $\alpha \mathrm{CD}$ complexes, the structure of the inclusion is determined by the small cavity of the host. The inclusion stoichiometry is $2: 1$, and the Raman spectra are consistent with a rigid structure, in which both substituent groups are inside the cavities of neighbouring $\alpha \mathrm{CD}$ hosts and the phenyl ring lies in the inter-rim region. The presence of differently bound water molecules and the red-shift of the $v C=O$ mode are interpreted in terms of the presence of hydrogen-bonding $(\mathrm{C}-\mathrm{H} \cdots \mathrm{O})$ interactions.

The wider cavities of the $\beta \mathrm{CD}$ and $\gamma \mathrm{CD}$ hosts allow a deeper inclusion of the guests, with less rigid structures. In the $\beta C D$ complexes, the results are consistent with a $1: 1$ inclusion stoichiometry, with full inclusion of the aromatic ring and leaving the substituent groups in the region of the rims. In the case of the $\gamma \mathrm{CD}$ complexes, the observed $1: 2$ inclusion stoichiometry leads to a 'liquidlike' distribution and interactions of the guest molecules.

\section{Acknowledgements}

The authors would like to thank Wacker Chemie GmbH, Germany, for their kind offer of the CDs and the Portuguese Foundation for Science and Technology - Unidade de Química-Física Molecular, Laboratório Associado CICECO and research project
POCTI/QUI/35408/99 (co-financed by the European community fund FEDER). The authors also thank Celeste Azevedo for performing the TG experiments.

\section{REFERENCES}

1. Bender ML, Komiyama M. Cyclodextrin in Chemistry. SpringerVerlag: Berlin, 1978.

2. Cambridge Structural Database System, Cambridge Crystallographic Data Center 12 Union Road, Cambridge CB2 1EZ, UK. (http://www.ccdc.cam.ac.uk/)

3. Zornoza A, Martín C, Sánchez M, Vélaz I, Piquer A. Int. J. Pharm. 1998; 169: 239.

4. Hees TV, Piel G, Hassonville SH, Evrard B, Delattre L. Eur. J. Pharm. Sci. 2002; 15: 347.

5. Fernandes CM, Vieira MT, Veiga FJB. Eur. J. Pharm. Sci. 2002; 15: 79.

6. Yazan Y, Sumnu M. STP Pharm. Sci 1994; 4: 128.

7. Loftsson T. Pharmazie 1998; 53: 733.

8. Pagington S. Chrm. Br. 1987; 23: 455.

9. Pagington JS. Developments in Food Flavours. Elsevier Applied Science: Barking, 1991.

10. Divakar S. J. Agric. Food Chem. 1990; 38: 940.

11. Dailey OD Jr, Bland JM, Trask-Morrell BJ. J. Agric. Food Chem. 1993; 41: 1767.

12. Szejtli J, Szente L, Mánky-Elöd E. Acta Acad. Sci. Hung. 1979; 101: 27.

13. Garbow JR, Gaede BJ. J. Agric. Food Chem. 1992; 40: 156.

14. Szejtli J. Chem. Rev. 1998; 98: 1743.

15. Several review articles published in Chem. Rev. 1998; 98.

16. Braga SS, Aree T, Imamura K, Vertut $P$, Boal-Palheiros I, Saenger W, Teixeira-Dias JJC. J. Inclusion Phenom. Macrocyclic Chem. 2002; 43: 115.

17. Netto-Ferreira JC, Ilharco LM, Garcia AR, Ferreira LFV. Langmuir 2000; 16: 10382.

18. Amado AM, Moreira da Silva AM, Ribeiro-Claro PJA, TeixeiraDias JJC. J. Raman Spectrosc. 1994; 25: 599.

19. Ribeiro-Claro PJA, Amado AM, Teixeira-Dias JJC. J. Raman Spectrosc. 1996; 27: 155.

20. Amado AM, Ribeiro-Claro PJA. J. Raman Spectrosc. 2000; 31: 971.

21. Giordano F, Novak C, Moyano JR. Thermochim. Acta 2001; 380: 123 , references cited therein.

22. Braga SS, Gonçalves IS, Ribeiro-Claro P, Lopes AD, Pillinger M, Teixeira-Dias JJC, Rocha J, Romão CC. Supramol. Chem. 2002; 14: 359.

23. Braga SS, Gonçalves IS, Pillinger M, Ribeiro-Claro P, TeixeiraDias JJC. J. Organomet. Chem. 2001; 632: 11.

24. Cunha-Silva L, Teixeira-Dias JJC. J. Phys. Chem. 2002; B106: 3323.

25. Choi S-H, Ryu E-N, Ryoo JJ, Lee K-P. J. Inclusion Phenom. Macrocyclic Chem. 2001; 40: 271.

26. Amado AM, Ribeiro-Claro PJA. J. Chem. Soc., Faraday Trans. 1997; 93: 2387.

27. Lima S, Gonçalves IS, Ribeiro-Claro PJA, Pillinger M, Lopes AD, Ferreira P, Teixeira-Dias JJC, Rocha J, Romão CC. Organometallics 2001; 20: 2191.

28. Veiga F, Teixeira-Dias JJC, Kedzierewicz F, Sousa A, Maincent P. Int. J. Pharm. 1996; 129: 63.

29. Li X-T, Li J-H, Zhang G-E, Xi G-X, Lou X-D. Thermochim. Acta 1995; 262: 165.

30. Miller FA, Harney BM. Appl. Spectrosc. 1970; 2: 291.

31. Frisch MJ, Trucks GW, Schlegel HB, Scuseria GE, Robb MA, Cheeseman JR, Zakrzewski VG, Montgomery JA Jr, Stratmann RE, Burant JC, Dapprich S, Millam JM, Daniels AD, Kudin KN, Strain MC, Farkas O, Tomasi J, Barone V, Cossi M, Cammi R, Mennucci B, Pomelli C, Adamo C, Clifford S, Ochterski J, Petersson GA, Ayala PY, Cui Q, Morokuma K, Malick DK, 
Rabuck AD, Raghavachari K, Foresman JB, Cioslowski J Ortiz JV, Baboul AG, Stefanov BB, Liu G, Liashenko A, Piskorz P, Komaromi I, Gomperts R, Martin RL, Fox DJ, Keith T, Al-Laham MA, Peng CY, Nanayakkara A, Challacombe M, Gill PMW, Johnson B, Chen W, Wong MW, Andres JL, Gonzalez C, Head-Gordon M, Replogle ES, Pople JA. Gaussian 98, Revision A.9. Gaussian Incorporated: Pittsburgh, PA, 1998.

32. Foresman JB, Keith TA, Wiberg KB, Snoonian J, Frisch MJ. J. Phys. Chem. 1996; 100: 16098.

33. Vaz PD, Ribeiro-Claro PJA. Chem. Phys. Lett. 2004; 390: 358.

34. Harata K, Uekama K, Otagiri M. Bull. Chem. Soc. Jpn. 1981; 54 1954.

35. Shibakami M, Sekiya A. J. Chem. Soc., Chem. Commun. 1992; 1742.

36. Tian S-J, Xi G-X, Cheng Q-T, Lou X-D, Li J-H. J. Therm. Anal. 1998; 53: 825.
37. Li X-T, Li J-H, Zhang G-E, Xi G-X, Lou X-D. Thermochim. Acta 1995; 262: 165.

38. Nyquist RA. Appl. Spectrosc. 1992; 46: 306.

39. Ribeiro-Claro PJA, Batista de Carvalho LAE, Amado AM. J. Raman Spectrosc. 1997; 28: 867.

40. Karger N, Amorim da Costa AM, Ribeiro-Claro PJA. J. Phys. Chem. 1999; A103: 8672.

41. Marques MPM, Amorim da Costa AM, Ribeiro-Claro PJA. J. Phys. Chem. 2001; A105: 5292.

42. Ribeiro-Claro PJA, Drew MGB, Félix V. Chem. Phys. Lett. 2002; 356: 318.

43. Ribeiro-Claro PJA, Marques MPM, Amado AM. Chemphyschem. 2002; 3: 599.

44. Britton D. J. Chem. Crystallogr. 1994; 24: 553.

45. Wilson EB. Phys. Rev. 1934; 45: 706.

46. Moreira da Silva AM, Amado AM, Ribeiro-Claro PJA, Empis J, Teixeira-Dias JJC. J. Carbohydr. Chem. 1995; 14: 677. 